\title{
CHANGES IN THE P WAVE OF THE HUMAN ELECTROCARDIOGRAM *
}

\author{
C. H. GODDARD, M.D. \\ BALTIMORE
}

The most important observations in regard to the " $\mathrm{P}$ " wave of the human electrocardiogram have been those concerning its changes in mitral stenosis. Various workers, including Einthoven, ${ }^{1}$ Krauss and Nicolai, ${ }^{2}$ and Samjoloff, ${ }^{3}$ have called attention to an increase in height and often also a broadening of the $\mathrm{P}$ wave in this disease. To quote the last:

Wir fanden ebenfalls bei Mitralstenose Verstärkung und meist auch Verlängerung der P-Erhebung. (We found likewise in mitral stenosis an augmentation, and generally also a prolongation of the $\mathrm{P}$ wave.)

Since the increase in the height of the $P$ wave has been thought due to the auricular hypertrophy resulting from the narrowing of the mitral ring, it would be reasonable to believe that auricular hypertrophy, the result of any other pathological change, would have the same effect. Hence it has been the custom at this station to consider high $\mathrm{P}$ waves as more or less indicative of auricular hypertrophy. In measuring the height of this wave we have considered the P-T, and disregarded the $P-R$, ratio. The $T$ wave is normally higher than the $P$, i. e., the P-T ratio is normally less than one. And so in cases in which the $T$ waves were of normal average height, and the $P$ - $T$ ratio equal to or greater than one in one or more derivations, the curve has been considered suggestive of auricular hypertrophy-increasingly so as more derivations were involved. When the $\mathrm{T}$ wave was inverted, actual changes in the $\mathrm{P}$ height have been used as criteria, and a $\mathrm{P}$ wave which to the eye was plainly higher than normal has been considered suggestive of auricular hypertrophy. When both $\mathrm{P}$ and $\mathrm{T}$ waves were very small and much below the normal size, a $\mathrm{P}-\mathrm{R}$ ratio of more than one has not been held to mean hypertrophy; $i$. e., we have felt that

\footnotetext{
* Submitted for publication May 24, 1915.

* From the Medical Clinic of the Johns Hopkins University.

1. Einthoven, W.: Le Télécardiogramme, Arch. internat. de physiol., 1906-7, iv, 148 .

2. Kraus, F., and Nicolai, G. F.: Ueber das Elektrokardiogramm unter normalen und pathologischen Verhältnissen, Berl. klin. Wchnschr., 1907, xliv, 812.

3. Samjoloff, A.: Ueber die Vorhoferhebung des Elektrokardiogramms bei Mitralstenose, München. med. Wchnschr., 1909, 1vi, 1943.
} 
hypertrophy should be considered only in those cases in which there was an actual as well as a proportional increase in the $\mathrm{P}$ height.

By way of checking up the relationship between the $P$ wave and auricular hypertrophy, the electrocardiograms of thirty-seven cases of clinical mitral disease on file at this station were examined, in which auricular hypertrophy might reasonably have been expected. These included twenty of insufficiency only, fourteen of combined

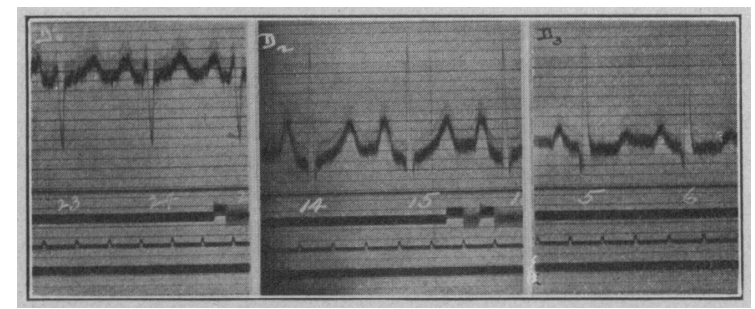

Fig. 1.-Case of mitral stenosis showing increase in height of $\mathrm{P}$ wave.

stenosis and insufficiency, and three of stenosis alone. The curves showed marked relative or actual exaggeration of the lieight of the $\mathrm{P}$ wave in twelve cases, or 33 per cent. It was moderately exaggerated in eight more, uncertainly exaggerated in five, and definitely small in the other twelve. Thus there was some relative increase in height in 54 per cent. of the cases studied. An example of the first group is shown in Figure 1, the electrocardiogram of R. K., white, aged 28. The diagnosis in her case was mitral stenosis and exophthalmic goiter.

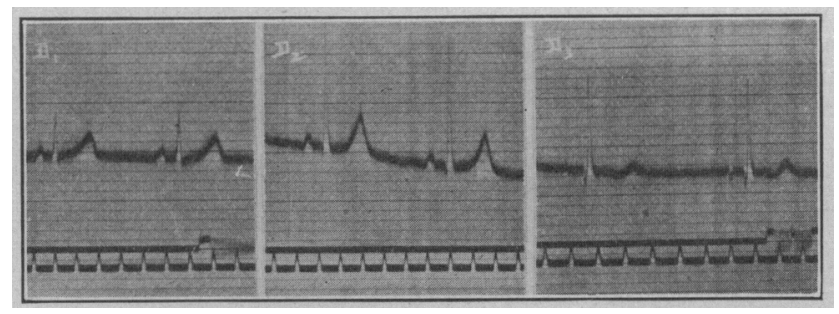

Fig. 2.-Case of mitral stenosis showing no increase in height of $P$ wave.

Her heart measured, to percussion, $10 \mathrm{~cm}$. to the left and $4 \mathrm{~cm}$. to the right in the fifth and fourth interspaces, and the patient showed the typical signs of mitral stenosis. This is the type of case from which a diagnosis of auricular hypertrophy would be made unhesitatingly if a high $\mathrm{P}$ wave be taken as pathognomonic of this condition.

On the other hand, Figure 2 shows the electrocardiogram of a typical case of mitral disease in which there is no increase in the height of the $\mathrm{P}$ wave. The patient, F. S., white, aged 14, had a clinical 
diagnosis of mitral stenosis and insufficiency and aortic insufficiency. His relative cardiac dulness measured $10 \times 5.5 \mathrm{~cm}$. in the fifth interspace. He had been admitted eight years previously with a diagnosis of chorea and mitral stenosis, so his cardiac changes were of long standing, and auricular hypertrophy to be expected. Yet the $\mathrm{P}$ wave is of normal size.

Five cases of the above series came to necropsy. Four of these showed auricular hypertrophy of varying degrees; the fifth slight dilatation of the right auricle only. This last and one other showed no increase in the size of the $\mathrm{P}$ wave; in the other three there was some increase, but this did not vary directly with the hypertrophy. Thus, one case of very slight hypertrophy showed a marked exaggeration of the $\mathrm{P}$ height, and one with much more marked hypertrophy a very slight exaggeration. It is to be noted that the only case in which the auricles were found tremendously dilated and hypertrophied, the mitral narrowing being very marked, was that of F. G., colored,

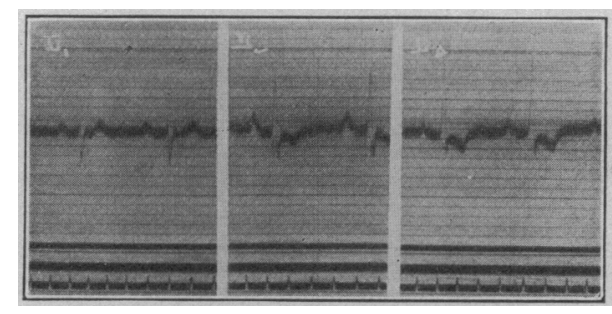

Fig. 3.-Case which showed at autopsy very marked dilatation and hypertrophy of the auricles. $\mathrm{P}$ wave increased in height in $\mathrm{D}_{\mathrm{z}}$ only.

aged 26, whose electrocardiogram is shown in Figure 3. It was taken three and a half months before death, the diagnosis being mitral stenosis and insufficiency. A high grade of auricular hypertrophy was probably then extant, as the cardiac symptoms were of three years' standing, yet, except for a relative enlargement in $D_{2}$ the height of the $\mathrm{P}$ wave is not increased, and its appearance would not suggest more than slight hypertrophy. It is noteworthy that the jugular tracings in this case showed a huge auricular "a" wave.

The matter was approached from another standpoint, and forty cases of electrocardiograms with high $\mathrm{P}$ waves were discovered in some seven hundred cases on file. The histories of the patients comprising this list were then examined. In four instances, the patients not being hospital cases, no history was available. Of the other thirtysix, sixteen, or 45 per cent, had a diagnosis of mitral disease. Thirteen others showed myocardial insufficiency, associated with syphilis, myocarditis, or chronic nephritis, auricular hypertrophy being a reasonable presumption. There were two cases of paroxysmal tachycardia, one 
of pulmonary tuberculosis with positive Wassermann test, two of hyperthyroidism, one with an associated pulmonary tuberculosis, and two of psychoneurosis, one with a positive Calmette test and one uncomplicated.

The electrocardiogram of this last is shown in Figure 4. The patient, Mrs. C., housewife, had suffered from nervousness, "dazed condition," and chronic constipation since the birth of her first and only child six years previously. Examination showed a normal woman with normal cardiovascular findings and a rather small heart. Her relative cardiac dulness measured $7 \times 3.5 \mathrm{~cm}$. in the fifth interspace. The electrocardiogram shows relatively large $\mathrm{P}$ waves in all derivations, and might readily be diagnosed one of auricular hypertrophy.

A study of the foregoing figures is conducive to the belief that although mitral disease with presumptive concomitant auricular hypertrophy and large $\mathrm{P}$ waves are associated in a considerable percentage of cases, this association is not a constant one. And it would seem

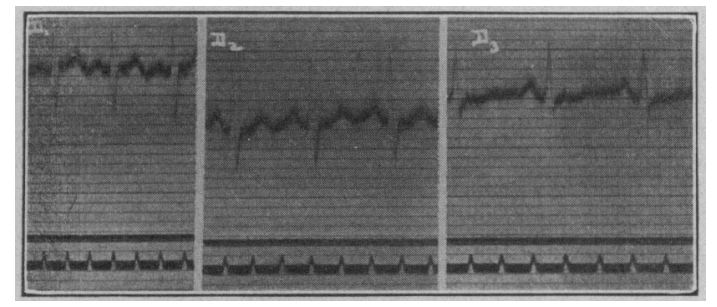

Fig. 4.-Case with clinically normal heart showing increase in height of $\mathrm{P}$ wave.

that while auricular hypertrophy probably in many instances exerts a causative influence, there must be many other factors which modify the height of the $\mathrm{P}$ wave. Indeed Einthoven ${ }^{4}$ has demonstrated experimentally that increase in the height of this wave may be produced by cutting the vagus in dogs. He reports that vagal section may be followed by a rise in the $\mathrm{P}$ wave to nearly three times its former height. Plainly no gross organic change can take place in the auricles during the course of such an experiment, and we must look for other factors to explain the results recorded.

Changes in the height of the $\mathrm{P}$ wave may occur from beat to beat, as Figure 5, the electrocardiogram of a case of complete heart block of luetic origin, shows. The auricular wave immediately following a ventricular systole is comparatively small but there is a progressive increase in the height of the $\mathrm{P}$ waves until the next ventricular response occurs, when the cycle is repeated. It might be suggested

4. Einthoven, W.: Weiteres über das Electrokardiogramm, Arch. f. d. ges. Physiol., 1908, cxxii, 537. 
C. H. GODDARD

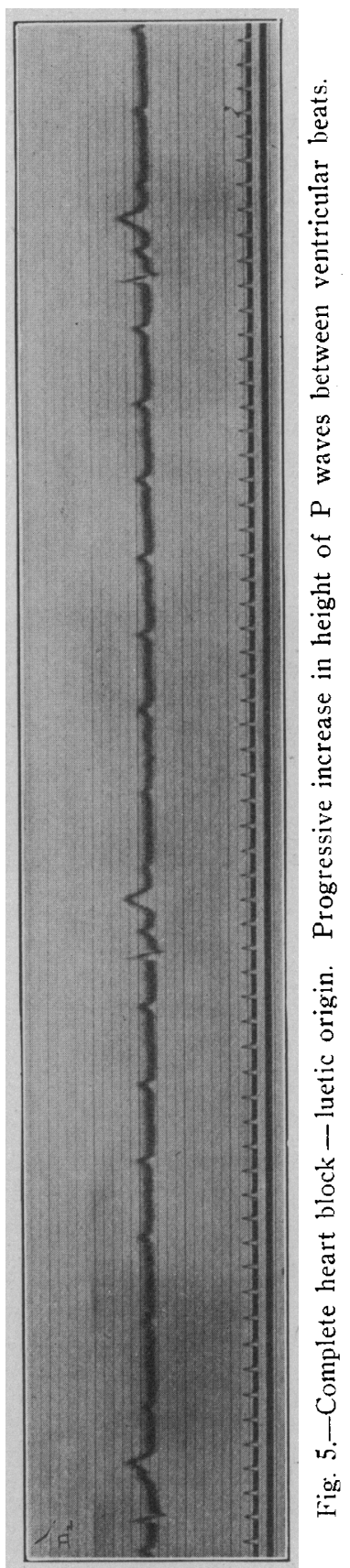

Downloaded From: http://archinte.jamanetwork.com/ by a University of California - San Diego User on 06/03/2015 
that each succeeding beat of the auricles, between ventricular beats, was working against greater pressure than the one immediately preceding, and that slight but progressively increasing functional dilatation was thus produced, such pressure and dilatation being relieved when the ventricle finally contracted. The idea of auricular dilatation exaggerating the height of the $P$ wave is rather a novel one, and not well supported in the electrocardiographic findings in the two cases of our series which showed auricular dilatation at necropsy.

A review of the above findings would incline one to the belief that whatever the association between high $\mathrm{P}$ waves, mitral disease, and auricular hypertrophy, the dogmatic assertion that all cases of mitral stenosis will show high $\mathrm{P}$ waves, or that all cases of high $\mathrm{P}$ waves mean auricular hypertrophy, would be open to grave chance of error.

In reviewing the $P$ waves of the seven hundred cases mentioned, the fact at once became apparent that inversion of this wave scarcely ever occurred except in the third derivation.

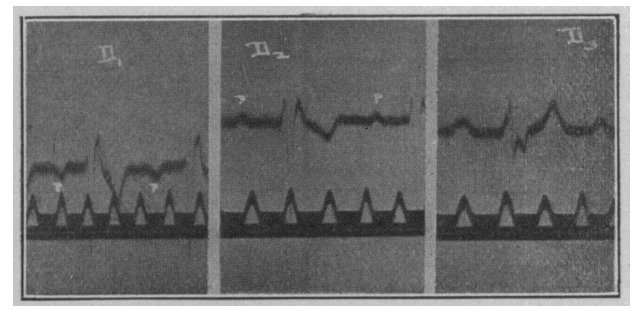

Fig. 6.-Same case as Figure 5, with normal sequence reestablished. $P$ wave inverted in $D_{1}$, upright in $D_{2}$ and $D_{3}$.

It seems advisable to link inverted and diphasic $P$ waves under one head, and, for simplicity, to speak of them all as "inverted," except where there is reason for differentiation. For the causative agents are apparently the same in both cases, and it is often difficult to classify a wave strictly under either heading. This is due to the fact that it may vary in appearance at different periods in the same curve, being now definitely inverted, now plainly diphasic.

To be specific, the $\mathrm{P}$ wave was inverted in the first derivation in but four cases of the entire series. Three of these were cases of situs inversus, in which such a phenomenon was to be expected. The fourth was the case of luetic heart block already referred to. The block passed off under treatment, and in an electrocardiogram taken later all waves were inverted in $\mathrm{D}_{1}$, as in situs inversus. The relations in the second and third derivations, however, differed from those found in situs inversus. At this time the conduction time was prolonged (Fig. 6). Excepting the cases of situs inversus, this is the only case in which we have seen inversion of the $P$ wave in $D_{1}$ without 
inversion in the other two derivations. Of additional interest is the fact that the electrocardiogram of this patient while in a state of complete block showed a normal upright $\mathrm{P}_{1}$ and $\mathrm{P}_{2}$ with a diphasic $\mathrm{P}_{3}$ (Fig. 7), while a subsequent tracing, of later date than Figure 6, has shown upright $\mathrm{P}$ waves in all derivations (Fig. 8). It is clear from this that changes in the direction of the $P$ wave are not necessarily constant when once observed in a given patient.

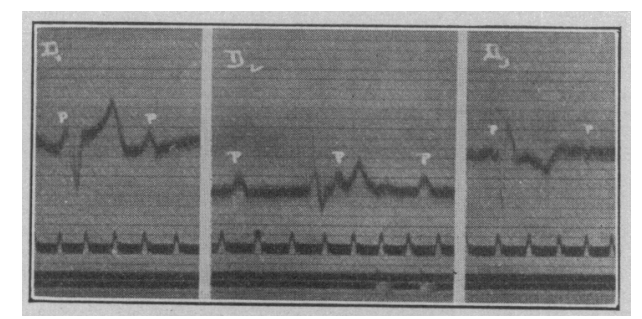

Fig. 7.-Same case as Figures 5 and 6 . Complete block. $P$ wave upright in $D_{1}$ and $D_{2}$, diphasic in $D_{s}$.

In a single instance, the $\mathrm{P}$ wave was diphasic in all derivations. The patient, R. S., colored, 35, was admitted in great decompensation with a right hydrothorax and a relative cardiac dulness extending 17 $\mathrm{cm}$. to the left in the sixth interspace. The Roentgen ray showed a large heart lying transversely, with an unexplained mass (aneurysm?) in the region of the right heart. Diagnosis was myocardial insufficiency, arteriosclerosis, chronic nephritis. He was discharged improved with a relative cardiac dulness of $13 \times 5 \mathrm{~cm}$. in the fifth and fourth interspaces.

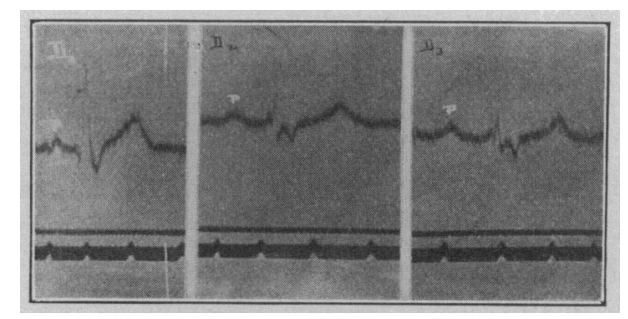

Fig. 8.-Same case as Figures 5,6 and 7. Block has disappeared. $P$ wave upright in all derivations.

The $P$ wave was diphasic or inverted seven times in $D_{2}$, in patients with varying clinical diagnoses. In all of these it was inverted in $\mathrm{D}_{3}$ also. In one case, R. Z., white, 23 , no cardiac lesion was made out; the diagnosis being neurasthenia. The heart was enlarged, however, the relative cardiac dulness measuring $11.5 \times 4.5 \mathrm{~cm}$. In this instance the $P$ wave varied in cycles, being upright, then diphasic, then inverted, 


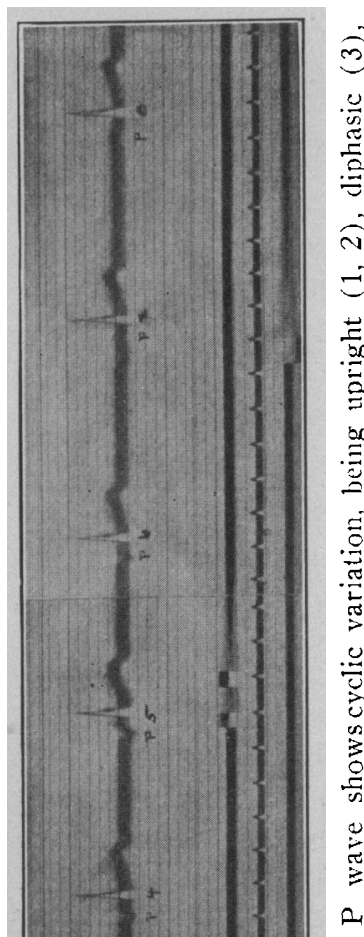

के

$\stackrel{4}{\circ}$

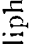

ลิ

$\Xi$

$\stackrel{5}{E}$

$\stackrel{\infty}{=}$

$\cong$

E

恶

$\because$

b

$\frac{0}{n}$

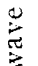

D.

$+\infty$

密.

0

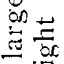

鴶

.

蒠

壱

응

is

胥

咜

-6

ถั

$\bigcup^{+\infty}$

oi

焉 
then diphasic, and finally upright again $\left(D_{2}\right)$. The duration of a cycle was too long to ascribe it to respiratory effect. The electrocardiogram showed a pulse rate of $50, P_{2}$ as described, diphasic $P_{3}$ and split $R_{3}$; otherwise normal (Fig. 9).

In seventy-five cases, about 11 per cent. of all on file, $\mathrm{P}_{3}$ was diphasic or inverted. It is to be remembered that all cases of such changes in $\mathrm{D}_{1}$ and $\mathrm{D}_{2}$ numbered together but twelve. Examination of the clinical histories naturally showed that heart lesions were present in the majority of instances, since it is not the practice here to take electrocardiograms of many cases outside the cardiac type. Nevertheless, several cases were available in which diagnoses such as "chronic appendicitis and enteroptosis," "hyperthyroidism," "psychoneurosis and neurasthenia," "atrophic cirrhosis of the liver, pellagra," were made, and in which the cardiac condition seemed normal; although in most of these a large relative cardiac dulness, suggestive of emphysema or pulmonary tuberculosis, made auricular changes possible. At least

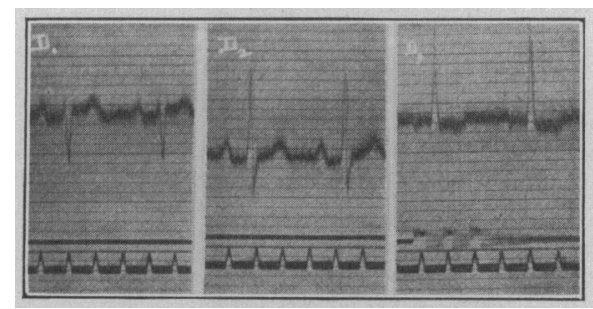

Fig. 10.-Case with clinically normal heart showing inverted $P$ wave in $D_{3}$.

three cases, however, appear to be above suspicion. The first was N. U., white, a neurotic girl of 16, with a diagnosis of hyperthyroidism, and a normal heart. The second (Fig. 10) was a case of periodical paralysis in a young man of 23 with a relative cardiac dulness of $9 \times 4.5 \mathrm{~cm}$., and a clinically normal heart. The third, M. T., white, aged 54, was a case of chronic cholelithiasis following typhoid fever. His relative cardiac dulness measured $8.5 \times 4 \mathrm{~cm}$. in the fifth and fourth interspaces. Following operation he died of hemorrhage. Autopsy showed normal auricles.

Another case that came to autopsy should be noted. The patient, T. S., colored, aged 65 , had had cardiac symptoms for a year and a half. The diagnosis was syphilis, mitral insufficiency, and chronic nephritis. The electrocardiogram, taken two weeks before death, showed beautiful inversion of $P_{2}$ and $P_{3}$. At autopsy the right auricle was slightly dilated, the left normal.

Seven of the thirty-seven mitral cases previously referred to showed inverted $\mathrm{P}_{3}$. In only one of these was there any relative 
enlargement of the $P$ wave. This was in P. J., a woman of 20 , diagnosis, mitral stenosis. There was progressive increase in the height of the $\mathrm{R}$ wave, the so-called "Right ventricular hypertrophy sequence."

An interesting feature was the discovery that 70 per cent. of all cases of inverted $\mathrm{P}$ wave showed the "left ventricular hypertrophy sequence," a progressive decrease in the $\mathrm{R}$ and increase in the $\mathrm{S}$ wave. These figures are not quite so impressive when we know that 47 per cent. of all the cases on file showed this sequence, but still they remain very significant. Twice only was the right ventricular hypertrophy sequence present. One of these cases was in P. J., referred to in the paragraph preceding. The other was that of a child of 8 years with a diagnosis of mitral stenosis and insufficiency, and aortic insufficiency.

It is worthy of note that in almost every instance in which neither ventricular sequence was present, interesting changes in the $Q$ and $S$ waves took place; i. e., a progressive increase or decrease in the size of one or both.

As to the causes of inverted $P$ waves, their marked tendency to appear only in $\mathrm{D}_{3}$, and their association with the left ventricular sequence, one can but speculate. Consideration of the facts at hand would lead to the impression that actual organic changes in the auricles are by no means necessary factors in the causation of the inverted $P$. Age may have an effect; only three of our series occurred in children (all with diseased hearts), but then the percentage of children's electrocardiograms on file is very small. It would seem, however, judging from the association between the inverted $P$ and the left ventricular sequence, that the former, as the latter, will tend to appear more frequently with advancing age. The left ventricular sequence appears to be rather a normal finding in persons past middle life, i. e., it can hardly be considered necessarily indicative of pathological conditions, as Bridgman ${ }^{5}$ has suggested. Similarly, although the inverted $\mathrm{P}$ is a less frequent finding, it would appear that it will tend to be found normally in a certain percentage of healthy adults.

Einthoven ${ }^{6}$ has demonstrated that vagal stimulation may so reduce the height of the $\mathrm{P}$ wave that it becomes diphasic. Why then may not other influences not at present recognized produce similar changes, the auricles remaining uninjured? Perhaps vagal effects have some part in the clinical findings as well as the experimental, but hardly a prominent one, for vagotonie was not a feature of the cases studied. Pulse rates varied between wide limits, as did blood pressure. Cardiac position and respiratory influence may well each play a part. Other, probably more important, factors remain to be determined.

5. Bridgman, E. W.: The Value of the Electrocardiogram in the Diagnosis of Cardiac Hypertrophy, The Archives Int. Med., 1915, xv, 487.

6. Einthoven, W.: Weiteres über das Elektrokardiogramm, Arch. f. d. ges. Physiol., 1908, cxxii, 540. 
1. Although mitral disease, with presumptive auricular hypertrophy, was accompanied in 54 per cent. of our cases by some relative increase in the size of the $\mathrm{P}$ wave, cases occur in which no such increase is found, and autopsy may reveal marked auricular hypertrophy which the electrocardiogram hardly suggested.

2. A considerable number, 45 per cent. in our series, of large $P$ waves are associated with mitral disease, but such waves also occur in other conditions and in persons with clinically normal cardiac findings.

3. Inversion of the $\mathrm{P}$ wave is commonly found in $\mathrm{D}_{3}$ only; in 70 per cent. of these cases in our series the phenomenon was associated with the "Left ventricular hypertrophy sequence."

4. Inverted $P$ waves occur at all ages. The size and shape of the $P$ wave may vary at different periods in the same curve, and an inverted $\mathrm{P}$ in one record may appear upright in a later tracing, and vice versa.

The causative factors in inversion of the $\mathrm{P}$ wave are yet to be determined.

I am indebted to Dr. E. W. Bridgman for many of my case records and other generous assistance. 